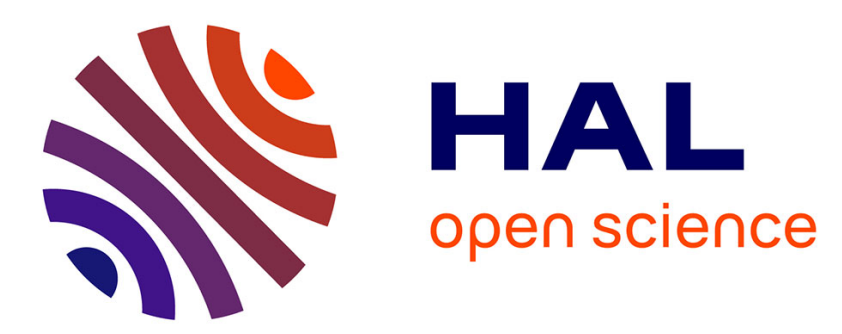

\title{
Towards Stabilization of Constant Power Loads Using IDA-PBC for Cascaded LC filter DC/DC Converters
}

\author{
Shengzhao Pang, Babak Nahid-Mobarakeh, Serge Pierfederici, Yigeng
}

Huangfu, Guangzhao Luo, Fei Gao

\section{- To cite this version:}

Shengzhao Pang, Babak Nahid-Mobarakeh, Serge Pierfederici, Yigeng Huangfu, Guangzhao Luo, et al.. Towards Stabilization of Constant Power Loads Using IDA-PBC for Cascaded LC filter DC/DC Converters. IEEE Journal of Emerging and Selected Topics in Power Electronics, 2021, 9 (2), pp.13021314. 10.1109/JESTPE.2019.2945331 . hal-02414856

\section{HAL Id: hal-02414856 \\ https://hal.univ-lorraine.fr/hal-02414856}

Submitted on 21 Oct 2021

HAL is a multi-disciplinary open access archive for the deposit and dissemination of scientific research documents, whether they are published or not. The documents may come from teaching and research institutions in France or abroad, or from public or private research centers.
L'archive ouverte pluridisciplinaire HAL, est destinée au dépôt et à la diffusion de documents scientifiques de niveau recherche, publiés ou non, émanant des établissements d'enseignement et de recherche français ou étrangers, des laboratoires publics ou privés. 


\title{
Towards Stabilization of Constant Power Loads Using IDA-PBC for Cascaded $L C$ filter DC/DC Converters
}

\author{
Shengzhao Pang, Student Member, IEEE, Babak Nahid-Mobarakeh, Senior Member, IEEE, \\ Serge Pierfederici, Yigeng Huangfu, Senior Member, IEEE, Guangzhao Luo, Member, IEEE, \\ and Fei Gao, Senior Member, IEEE
}

\begin{abstract}
This paper proposes a modified Interconnection and Damping Assignment Passivity-Based Control (IDA-PBC) for $D C / D C$ converter cascaded with $L C$ filter. The plant is modeled using Port-Controlled Hamiltonian (PCH) form. The main objective is to stabilize the cascaded system in case the system supplies Constant Power Load (CPL). To solve the instability issues caused by tightly controlled cascaded systems, the IDA-PBC based on an overall PCH model including $L C$ input filter and DC/DC converter is established. Moreover, to ensure that the proposed IDA-PBC admits one unique solution, an adaptive interconnection matrix is designed to build the internal links in the PCH model. Furthermore, in order to improve the implementation on an on-board DC microgrid application with time-varying CPLs, a modified IDA-PBC algorithm is proposed based on the error between the state vector and the desired operating point, which might be variable. The closed-loop Hamiltonian function is chosen as the Lyapunov candidate function to guarantee that the system operates in a stable manner. The virtual damping assignment technique is addressed to tune the dynamic characteristic of the closed-loop system. Simulation and experimental results are carried out to illustrate the proposed method's effectiveness.
\end{abstract}

Index Terms - Stabilization, Constant Power Load (CPL), DC/DC converter, $L C$ filter, Interconnection and Damping Assignment (IDA), Passivity-Based Control (PBC), PortControlled Hamiltonian system (PCH), microgrid, More Electric Aircraft (MEA).

\section{NOMENCLATURE}

CPL Constant Power Load

IDA-PBC Interconnection and Damping Assignment Passivity-Based Control.

PCH Port-Controlled Hamiltonian system.

S. Pang is with the Groupe de Recherche en Energie Electrique de Nancy, École Nationale Supérieure d'Électricité et de Mécanique, Université de Lorraine, Nancy 54052, France, and also with the School of Automation, Northwestern Polytechnical University, Xi'an 710072, China (e-mail: shengzhao.pang@univ-lorraine.fr).

B. Nahid-Mobarakeh is with the Groupe de Recherche en Energie Electrique de Nancy, École Nationale Supérieure d'Électricité et de Mécanique, Université de Lorraine, Nancy 54052, France (e-mail: babak.nahidmobarakeh@univ-

$\begin{array}{ll}\text { POL } & \text { Point-Of-Load converter } \\ H(x) & \text { Hamiltonian function (Energy storage } \\ & \text { function) } \\ H_{d}(x) & \text { Closed-loop Hamiltonian function. } \\ R, R_{d} & \text { Dissipation matrix and damping matrix. } \\ J, J_{d} & \text { Interconnection matrix and desired } \\ & \text { interconnection matrix. } \\ K_{1}, K_{2}, \text { and } K_{3} & \text { Adaptive coefficients in matrix } J_{d} . \\ u, d & \text { Switch command and duty cycle. } \\ \xi, Q & \text { Disturbance and storage element matrix. } \\ i_{f}, v_{f} & \text { LC filter inductor current and capacitor } \\ & \text { voltage. } \\ i_{L}, v_{o} & \text { DC/DC boost converter inductor current and } \\ & \text { capacitor voltage. } \\ i_{f d}, V_{f d} & \text { Desired value of } L C \text { filter inductor current } \\ i_{d}, V_{d} & \text { and capacitor voltage. } \\ & \text { Desired value of boost converter inductor } \\ x & \text { current and capacitor voltage. } \\ & \text { State variable, } i . e ., x=\left[x_{1} x_{2} x_{3} x_{4}\right]^{\mathrm{T}}=\left[i_{f} v_{f} i_{L}\right. \\ x_{d} & \left.v_{o}\right]^{\mathrm{T}} \text {. } \\ & \text { Desired equilibrium point, } i . e ., x_{d}=\left[x_{1 d} x_{2 d} x_{3 d}\right. \\ \varepsilon & \left.x_{4 d}\right]^{\mathrm{T}}=\left[i_{f d} V_{f d} i_{d} V_{d}\right]^{\mathrm{T}} . \\ V_{r e f} & \text { Error variable, } i . e ., \varepsilon=x-x_{d} . \\ & \text { Output voltage reference. }\end{array}$

\section{INTRODUCTION}

TN THE aerospace field, more and more hydraulic and $I_{\text {pneumatic actuating devices are replaced by electric }}$ actuators. This trend is known as the "More Electric Aircraft" (MEA). In this concept, the whole system stabilization, flexible system configuration, and high-power delivery capability are mainly considered by the aircraft industry [1] [2] [3].

lorraine.fr).

S. Pierfederici is with the Laboratoire d'Energétique et de Mécanique Théorique et Appliquée, École Nationale Supérieure d'Électricité et de Mécanique, Université de Lorraine, Nancy 54054, France (e-mail: serge.pierfederici@univ-lorraine.fr).

Y. Huangfu and G. Luo are with the School of Automation, Northwestern Polytechnical University, Xi'an 710072, China (e-mail: yigeng@nwpu.edu.cn; guangzhao.luo@nwpu.edu.cn).

F. Gao is with the FEMTO-ST Institute and the FCLAB, Universite Bourgogne Franche-Comté, UTBM, Belfort 90010, France (e-mail: fei.gao@utbm.fr). 
A typical DC distribution system for MEA is shown in Fig.1 [4] [5]. This system can be considered as an on-board microgrid. The source side converters provide a regulated DC voltage to the distribution bus. Since the DC-bus voltage is not suitable for the load side, the point-of-load (POL) converters are used to adjust the voltage level [6]. An $L C$ filter is introduced between the input and output side of the DC-bus to limit the Electromagnetic Interferences (EMI) and harmonic effect [7] [8] [9] [10]. In addition, for this application, due to the tightly regulated power electronics behavior, these loads can be considered as the Constant Power Load (CPL) [11] [12]. However, these filters, DC/DC converters, as well as the CPLs, will greatly impact on the stability and robustness of the onboard DC microgrids [2] [7].

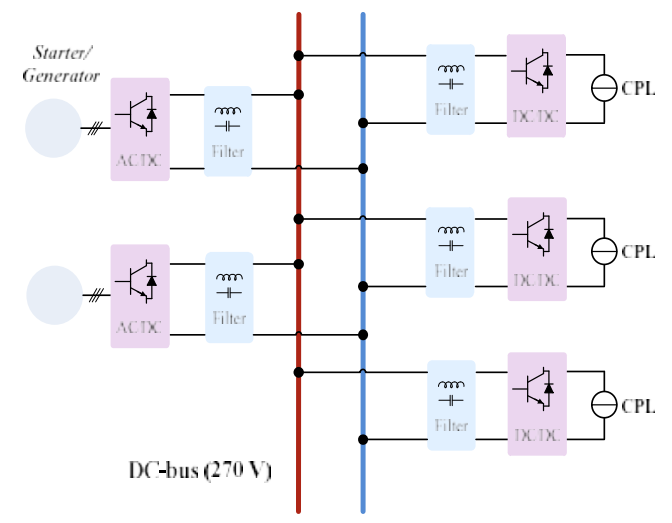

Fig. 1. Typical DC microgrid of more electric aircraft.

Moreover, this system may have a time-varying structure. In fact, a normal flight has 6 to 7 phases. They are namely taxiing, takeoff, climb, cruise, descent, approach, and landing. Each flight phase corresponds to a different operating condition [13]. Besides, changes in the flight phase also signify that the load is switched accordingly. This feature poses a growing challenge when the CPL is connected to the on-board DC microgrid system [4] [12] [14]. Several nonlinear control approaches have been reported in the literature regarding the stability problems of DC microgrids containing CPLs. An adaptive backstepping controller is developed in [1]. In [15], a Takagi-Sugeno (TS) based model predictive controller (MPC) is presented to stabilize the networked DC microgrids. Moreover, the extended Kalman filter is complemented to the MPC to estimate the power values of the CPL [16]. In [17] and [18], a sliding mode control and a robust non-fragile fuzzy control are introduced to ensure the stability of the closed-loop system. In [19], a reset gain-scheduling controller is designed to guarantee the closedloop stability of the DC microgrid through the continuous-time Lyapunov theory.

Likewise, the time-varying structure is also hard to analyze the stability of the proposed system. The stability analysis approach can be commonly categorized into two classes: smallsignal analysis and large-signal analysis. Regarding the smallsignal analysis, the impedance specifications (Middlebrook criterion, MGMP criterion, et al) are less suitable for on-board DC microgrids due to the conservative nature [5] [7]. The state- space models can also be considered with Lyapunov's indirect method to analyze the stability of the microgrid. However, they need a detailed model of the system, including control strategies, which is hard to meet in practice [9]. In case that a detailed model is available, its order is generally high. Authors in [20] suggest a method to reduce the order of the system for stability analysis. Meanwhile, this type of technique is very conservative. Regarding the large-signal analysis, the reverse trajectory tracking approach is a graphical scheme that is hard to apply in high-dimensional systems [4]. A frequently used approach is based on TS multi-modeling. The computational complexity of the TS multi-models increases exponentially with the number of loads (NP-problem). So, the number of CPLs limits the effective use of this approach [21]. Likewise to state-space approaches, the whole system's comprehensive model is required to the Block Diagonalized Quadratic Lyapunov Function (BDQLF) method and Brayton-Moser's mixed potential method [22] [23]. Consequently, these methods are not suitable for the time-varying on-board DC microgrids where several sources and loads interact.

Therefore, the stability analysis of on-board DC microgrids calls for a new tool that avoids dealing with high-order models without leading to conservative results. Such a tool is expected to determine the entire system stability based on the stability of its subsystems. It means that the stability of every single subsystem in the microgrid should be guaranteed first. Then, the whole system stability is determined considering the interconnection of these subsystems [13] [24].

The Passivity-Based Control (PBC) is a good candidate to meet the above-mentioned requirements. According to the passivity definition, an important benefit of the PBC is that the passivity property is preserved in arbitrary interconnections. So, it defines a controller design methodology that ensures the system stability by rendering it passive. Then, if the passive ensured subsystems are interlinked in feedback or in parallel form, the whole system is also passive and stable [11] [25] [26].

In the literature, the PBC using Euler-Lagrange (EL) models and Port-Controlled Hamiltonian (PCH) models have been introduced for providing the generalized integrated structures [27] [28] [29]. However, the EL models might not be suitable for the electrical and the electromechanical systems owing to the total energy shaping problem [30]. Therefore, the PCH modeling has been selected in this paper. The PBC based on $\mathrm{PCH}$ models is named Interconnection and Damping Assignment Passivity-Based Control (IDA-PBC).

A considerable amount of research using IDA-PBC has been done recently in different fields, such as synchronous motor drive [29], DC/DC converters [13] [31], three-phase inverters [32], AC/AC power conversion [33], solid-state transformers [34] and robot manipulators [35]. The main notions of PCH and IDA-PBC are given in [30] [36], and references therein. In this paper, a modified IDA-PBC technique for DC/DC converters cascaded with $L C$ filter supplying CPL is presented.

As mentioned earlier, the first step to ensure the stability of an on-board microgrid is to make sure that all subsystems in the microgrid are passive. To do this latter, a passivity-based controller can be developed and implemented on the subsystem 
level. In this paper, we focus on a subsystem containing an input $L C$ filter, a DC/DC converter and a CPL. Such subsystem appears frequently in on-board microgrids. Compared with the above-mentioned work in the literature, the main contributions of the conducted research here can be summarized as follows:

1) Stabilization of POL conv. + CPL through IDA-PBC based on the overall PCH modeling, including LC input filter:

Previous studies of IDA-PBC do not provide much attention to the $L C$ filter which closely affects the dynamic behavior of the system. From the impedance point of view, the interaction between $L C$ filter and DC/DC converter might influence the system dynamic performance. Coupled with $L C$ filter's uncontrollable feature, the risk of instability will significantly increase. In this paper, based on the $\mathrm{PCH}$ framework, all the dynamics, or equivalently energy storage units, in the whole system are considered in the Hamiltonian function (Energy storage function). Then, an overall $\mathrm{PCH}$ model containing $L C$ filter and $\mathrm{DC} / \mathrm{DC}$ converter is obtained. This overall $\mathrm{PCH}$ model will be used to prove the passivity and stability of the system and to generate the unique control law. Indeed, the $L C$ filter and the converter constitute the studied system. So, the dynamic behavior due to interactions between the filter and the converter are taken into account during the development of the IDA-PBC technique. Thanks to the overall PCH model, the $L C$ filter's voltage and current are considered in the control law, which is not the case of most control laws in the literature. Then, the stability of the system is ensured by selecting the closedloop Hamiltonian function as the Lyapunov candidate function.

\section{2) Unique control law with the adaptive interconnection matrix:}

Motivated by a recent result in [31], the final control law is generally derived from a partial equation of $\mathrm{PCH}$ models. Indeed, by using the $\mathrm{PCH}$ form, the total stored energy is considered in the Hamiltonian function, while all the equations are included and satisfied in the passivity and stability proof. So, the control law should take into account all the information of the PCH system, and it should be the unique solution to all the equations. How to link all the equations and obtain a unique control law it is of great interest. In this paper, an adaptive interconnection matrix is developed to achieve this mission. More specifically, we introduce three time-varying coefficients to give the additional degree of freedom, thereby solving the overall $\mathrm{PCH}$ function in a unique manner.

\section{3) Taking into account $x_{d}$ and its variations:}

Conventional IDA-PBC in the literature suppose the desired equilibrium point $x_{d}$ is always constant. However, the desired equilibrium point is related to the actual operating conditions and it varies over time. The above assumption (constant $x_{d}$ ) is satisfied only if the load does not change or it changes very slowly. However, we cannot reach this assumption in MEA applications. In practice, loads are time-varying due to variable operating conditions. To consider variable $x_{d}$, a modified IDA$\mathrm{PBC}$ and the mathematical proof of stability are presented in this paper. The modified IDA-PBC is based on the error between the state variable and the desired equilibrium point. Consequently, the proposed control law takes into account variations of CPLs and so those of $x_{d}$.

Although the underlying concept is similar to [5], some main differences can be noted: 1) The model is more realistic, i.e. some parasitic elements have been considered in this paper and their effects on the control and the stability are studied; 2) A known controlled load (tightly controlled buck converter) is used instead of the ideal CPL. New simulation and experimental results are given in this case: 2.1) An in-depth study of the damping assignment technique and the output voltage reference tracking are presented here. 2.2) The impact of the input voltage disturbances (step change and sinusoidal variations) on the regulation of the output voltage is studied. It is an important point because in practice, the input voltage can be provided by a rectifier or another converter and is likely variable.

This paper contains six sections. In Section II, the class of $\mathrm{PCH}$ models and the IDA-PBC methodology are briefly described. Section III is about the description of the studied system and its PCH model. The proposed modified IDA-PBC, as well as the stability proof and the control law implementation, are detailed in Section IV. Simulation and experimental results are given in Section V, and concluding remarks in Section VI.

\section{II.REVIEW OF THE PORT-CONTROLLED HAMILTONIAN AND THE INTERCONNECTION AND DAMPING ASSIGNMENT PASSIVITY- BASED CONTROL}

The class of PCH models and the IDA-PBC methodology related to this paper are briefly recalled in this section. Some properties and definitions are presented here for further details.

\section{A. Concept of PCH}

The dynamical system is said to be the port-controlled Hamiltonian system with dissipation, only if the system can be expressed as:

$$
\dot{x}=[J(x)-R(x)] \frac{\partial H}{\partial x}(x)+g(x) u+\eta
$$

where $x \in R^{n}, J(x)$ is named as the interconnection matrix such that $J(x)=-J^{\mathrm{T}}(x)$ (skew-symmetric) and $R(x)$ is known as the dissipation matrix such that $R(x) \geq 0$ (positive semi-definite). Moreover, $H(x)=x^{T} Q x$ is the total stored energy called Hamiltonian function. $Q$ represents the energy storage elements. $\eta$ corresponds to the disturbances dependent or independent on the state variables. $g(x)$ and $u$ denote the input matrix and the control vector respectively [13] [36].

\section{B. Basic Idea of the IDA-PBC}

The main point of the IDA-PBC is to assign a desired energy storage function with respect to a desired equilibrium point $x_{d}$ by modifying the desired interconnection matrix $J_{d}(x)$, damping matrix $R_{d}(x)$ and control law (called reshaping). It is necessary to choose a closed-loop Hamiltonian function $H_{d}(x)$, which admits a strict (local) minimum at $x_{d}$ to guarantee the system stability [5] [31] [36]. The resulting closed-loop system is given below, 


$$
\dot{x}=\left[J_{d}(x)-R_{d}(x)\right] \frac{\partial H_{d}}{\partial x}(x)
$$

Moreover, the following equations with respect to $J_{a}(x), R_{a}(x)$ should be satisfied,

$$
\begin{aligned}
& J_{d}(x)=J(x)+J_{a}(x)=-J_{d}{ }^{\mathrm{T}}(x) \\
& R_{d}(x)=R(x)+R_{a}(x)=R_{d}{ }^{\mathrm{T}}(x) \geq 0
\end{aligned}
$$

Here, the closed-loop Hamiltonian function (storage function) is defined as,

$$
H_{d}(x)=\left(x-x_{d}\right)^{\mathrm{T}} Q\left(x-x_{d}\right) \geq 0
$$

Then, we consider the closed-loop Hamiltonian function namely $V=H_{d}(x)$, is the Lyapunov function candidate. If the desired equilibrium point $x_{d}$ is arbitrary constant, the derivative of the closed-loop Hamiltonian function can be written as,

$$
\dot{V}=\left[\frac{\partial H_{d}(x)}{\partial x}\right]^{\mathrm{T}} \dot{x}=-\left[\frac{\partial H_{d}(x)}{\partial x}\right]^{\mathrm{T}} R_{d} \frac{\partial H_{d}(x)}{\partial x} \leq 0
$$

$H_{d}(x)$ is non-increasing, hence it qualifies as the Lyapunov function. The desired dynamical system is stable in the sense of Lyapunov. The final objective is to obtain a static state feedback control signal $u$ by,

$$
\begin{aligned}
{[J(x)-R(x)] \frac{\partial H}{\partial x} } & (x)+g(x) u+\eta \\
= & {\left[J_{d}(x)-R_{d}(x)\right] \frac{\partial H_{d}}{\partial x}(x) }
\end{aligned}
$$

It is worthwhile to note that, for the case $J_{a}(x)=R_{a}(x)=0$, the control law is derived from natural interconnection and damping. Hence, the interconnection matrix cannot be modified, and the virtual damping cannot be injected into the system [13].

\section{III.PRESENTATION OF THE SYSTEM}

\section{A. System Description}

Fig. 2 shows the topological structure of the DC/DC converter cascaded $L C$ filter supplying CPL.

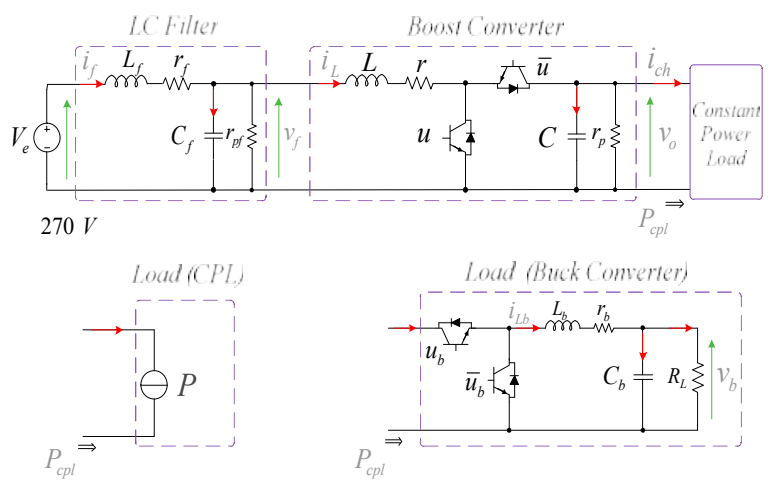

Fig. 2. The topology of the studied system.

It is worthwhile to mention that, the ideal CPL does not exist in practice. As described earlier, the tightly controlled converter load behaves like CPL. Therefore, it is a reasonable and effective way to assume and model the CPL as a tightly regulated converter. In this paper, a CPL is implemented by a tightly regulated buck converter, which uses sliding mode control to provide the energy to a resistive load.

Here, only the capacitor insulation resistance (or capacitor leakage resistance) $r_{p f}$ and $r_{p}$ are considered. Indeed, the equivalent series resistance (ESR) of the capacitor is also another important parameter. However, the proposed IDA-PBC is a kind of control approach based on the $\mathrm{PCH}$ framework. According to the definition of the IDA-PBC and PCH, the dynamical system is said to be the $\mathrm{PCH}$ system with dissipation, only if the system can be expressed as equation (1) (see Section II). If the model is too complex to be described in the form of (1), the IDA-PBC will no longer apply. Unfortunately, considering the ESR in the model will lead us to this situation. Therefore, the ESR is not taken into account in this work.

\section{B. PCH Models Applied}

Consider the above-mentioned system described in the state space, a model for the filter and DC/DC converter can be written as follows, the $L C$ filter dynamics:

$$
\begin{aligned}
& L_{f} \dot{i}_{f}=V_{e}-i_{f} r_{f}-v_{f} \\
& C_{f} \dot{v}_{f}=i_{f}-v_{f} / r_{p f}-i_{L}
\end{aligned}
$$

And the boost converter dynamics:

$$
\begin{aligned}
& L \dot{i}_{L}=V_{f}-i_{L} r-(1-d) v_{o} \\
& C \dot{v}_{o}=(1-d) i_{L}-v_{o} / r_{p}-i_{c h}
\end{aligned}
$$

Assuming that $x=\left[\begin{array}{llll}x_{1} & x_{2} & x_{3} & x_{4}\end{array}\right]^{\mathrm{T}}=\left[\begin{array}{llll}i_{f} & v_{f} & i_{L} & v_{o}\end{array}\right]^{\mathrm{T}}$ represents the state variables, while $Q=\operatorname{diag}\left(L_{f} / 2, C_{f} / 2, L / 2, C / 2\right)$ is the system energy storage elements. In this respect, the total stored energy in the system is denoted as the Hamiltonian function,

$$
\begin{aligned}
H(x) & =\frac{1}{2} L_{f} x_{1}^{2}+\frac{1}{2} C_{f} x_{2}{ }^{2}+\frac{1}{2} L x_{3}^{2}+\frac{1}{2} C x_{4}^{2} \\
& =x^{\mathrm{T}} Q x
\end{aligned}
$$

According to (1), (8), (9) and (10), the dynamics of the $L C$ filter and boost converter are defined by $\mathrm{PCH}$ models of the form,

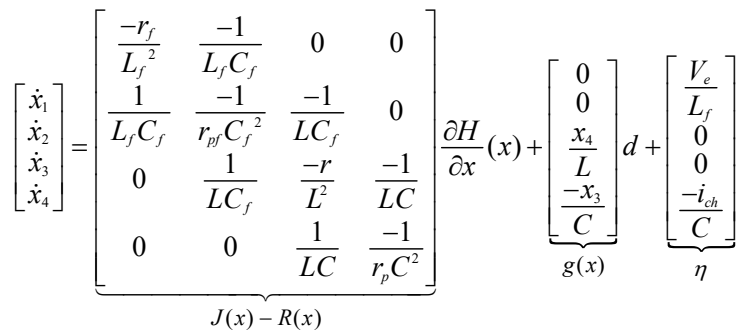

where the dissipation matrix is expressed as,

$$
R=\operatorname{diag}\left(\begin{array}{llll}
\frac{r_{f}}{L_{f}{ }^{2}} & \frac{1}{r_{p f} C_{f}{ }^{2}} & \frac{r}{L^{2}} & \frac{1}{r_{p} C^{2}}
\end{array}\right)
$$




\section{Design of THE Proposed Control Algorithm}

\section{A. Problem Description}

Consider the application introduced in the Section I, the timevarying DC microgrids consisting of multiple cascaded or parallel converters and filters. They are interlinked and interact with each other. Therefore, the desired equilibrium point $x_{d}$ in each converter is related to their disturbances $\eta$. That is,

$$
x_{d}=f(\eta)
$$

In practice, $\eta$ is the measured variables which only depend on the actual operating conditions of the load. Thus, the firsttime derivative of the closed-loop Hamiltonian function should be written as

$$
\dot{V}=\left[\frac{\partial H_{d}\left(x, x_{d}\right)}{\partial x}\right]^{\mathrm{T}} \dot{x}+\left[\frac{\partial H_{d}\left(x, x_{d}\right)}{\partial x_{d}}\right]^{\mathrm{T}} \cdot \frac{\partial x_{d}}{\partial \eta} \cdot \dot{\eta}
$$

It can clearly be seen, the previous stability proof in (6) is satisfied only under the assumption that $x_{d}$ is always a constant value. In practice, if the load never changes or changes very slowly, we can approximate that $x_{d}$ is a constant value. However, in the proposed on-board DC microgrid with time-varying CPLs, this assumption is invalid and the previous stability proof is no longer satisfied.

\section{B. Proposed Modified IDA-PBC and Its Proof}

It should be noted that the desired equilibrium point $x_{d}$ is a sole function of $\eta$ and it is independent from the state variables $x$. So, $\partial H_{d} / \partial \varepsilon=\partial H_{d} / \partial x$ where the tracking error is defined by $\varepsilon=x-x_{d}$. To make sure that this error converges asymptotically to zero, we define the following dynamic model for the tracking error:

$$
\dot{\varepsilon}=\left[J_{d}(x)-R_{d}(x)\right] \frac{\partial H_{d}}{\partial \varepsilon}(x)
$$

It is important to notice that equation (15) represents the desired model for the tracking error where the closed-loop Hamiltonian function (storage function) $H_{d}(x)$ is rewritten as,

$$
H_{d}(x)=\varepsilon^{\mathrm{T}} Q \varepsilon
$$

Then, the above function is defined as a Lyapunov function candidate $V=H_{d}(x) \geq 0$. The time derivative of this function is given by,

$$
\begin{aligned}
\dot{V} & =\left[\frac{\partial H_{d}(x)}{\partial \varepsilon}\right]^{\mathrm{T}} \dot{\varepsilon}=-\left[\frac{\partial H_{d}(x)}{\partial \varepsilon}\right]^{\mathrm{T}} R_{d} \frac{\partial H_{d}(x)}{\partial \varepsilon} \\
& =-4 \varepsilon^{\mathrm{T}} Q^{\mathrm{T}} R_{d} Q \varepsilon<0
\end{aligned}
$$

Obviously, $H_{d}(x)$ is a non-increasing function with time. Therefore, it can be qualified as the Lyapunov function, and $x_{d}$ is an asymptotically stable equilibrium of the closed-loop system.

Then, we replace $\dot{\varepsilon}$ by $\dot{x}-\dot{x}_{d}$ in (15), the new feedback control action satisfying (1) and (15) is obtained by,

$$
\begin{aligned}
{[J(x)-R(x)] \frac{\partial H}{\partial x} } & (x)+g(x) u+\eta \\
& =\left[J_{d}(x)-R_{d}(x)\right] \frac{\partial H_{d}}{\partial \varepsilon}(x)+\dot{x}_{d}
\end{aligned}
$$

\section{Implementation of LC Filter with Boost Converter}

In the proposed IDA-PBC based on PCH form, the control law is related to the selection of desired interconnection and damping matrices. The damping matrix should always positive semi-definite and the interconnection matrix is relatively free in structure. Thus, the interconnection matrix is a good candidate for building internal links and adding the additional degree of freedom in the PCH models. The desired interconnection and damping matrices in the close-loop PCH models are defined as follows,

$$
\begin{aligned}
& J_{d}=J+\underbrace{\left[\begin{array}{cccc}
0 & -K_{3} & 0 & 0 \\
K_{3} & 0 & -K_{2} & 0 \\
0 & K_{2} & 0 & -K_{I} \\
0 & 0 & K_{I} & 0
\end{array}\right]}_{J a} \\
& R_{d}=\operatorname{diag}\left(\begin{array}{llll}
\frac{r_{1}}{L_{f}{ }^{2}} & \frac{r_{2}}{C_{f}{ }^{2}} & \frac{r_{3}}{L^{2}} & \frac{r_{4}}{C^{2}}
\end{array}\right)
\end{aligned}
$$

The variables $K_{1}, K_{2}$, and $K_{3}$ are evenly distributed among the rows of the desired interconnection matrix $J_{d}$, internal links are thereby established in the $\mathrm{PCH}$ framework. Moreover, these variables vary with time and equilibrium point. So, $J_{d}$ is an adaptive interconnection matrix in the proposed IDA-PBC.

It is worthwhile to mention that, $J_{a}$ and $J$ are not necessary to have the same form. In order to make the solution easier to calculate, we choose $J_{a}$ and $J$ to have the same form in this paper. The closed-loop Hamiltonian function $H_{d}(x)$ represents the desired total stored energy in the $L C$ filter and boost converter,

$$
\begin{aligned}
H_{d}(x)= & \frac{1}{2} L_{f}\left(x_{1}-x_{1 d}\right)^{2}+\frac{1}{2} C_{f}\left(x_{2}-x_{2 d}\right)^{2} \\
& +\frac{1}{2} L\left(x_{3}-x_{3 d}\right)^{2}+\frac{1}{2} C\left(x_{4}-x_{4 d}\right)^{2} \\
= & \left(x-x_{d}\right)^{\mathrm{T}} Q\left(x-x_{d}\right)
\end{aligned}
$$

where $x_{d}=\left[\begin{array}{llll}x_{1 d} & x_{2 d} & x_{3 d} & x_{4 d}\end{array}\right]^{\mathrm{T}}=\left[\begin{array}{llll}i_{f d} & V_{f d} & i_{d} & V_{d}\end{array}\right]^{\mathrm{T}}$ denotes the desired equilibrium point with respect to $x=\left[\begin{array}{llll}x_{1} & x_{2} & x_{3} & x_{4}\end{array}\right]^{\mathrm{T}}=\left[\begin{array}{lll}i_{f} v_{f} & i_{L} & v_{o}\end{array}\right]^{\mathrm{T}}$. It should meet the circuit characteristic requirements and operating conditions. In this case, the desired value $V_{d}$ is the required output voltage $V_{\text {ref }}\left(V_{\text {ref }}>270 \mathrm{~V}\right)$ for supplying the constant power load. The desired value $i_{d}$ is computed by power conservation,

$$
\left\{\begin{array}{l}
i_{d}=\frac{V_{e}^{*}}{2 r^{*}}\left(1-\sqrt{1-\frac{P+V_{d}^{2} / r_{p}}{P_{\max }^{*}}}\right) \\
P_{\max }^{*}=\frac{V_{e}^{* 2}}{4 r^{*}}
\end{array}\right.
$$

where,

$$
V_{e}^{*}=\frac{r_{p f}}{r_{f}+r_{p f}} V_{e}
$$




$$
r^{*}=r+\frac{r_{f} r_{p f}}{r_{f}+r_{p f}}
$$

In [31], the CPL power $P$ is considered as a constant value which is always known. However, load power varies in time and only depend on the equilibrium point and the actual operating condition. Indeed, the converter and its controller are not informed during the load variations, the only choice is to measure it through the sensor. Here, the CPL power $P$ is replaced by $v_{o} i_{c h}$ (constant) in equation (22). Moreover, two other desired values are given by (24) and (25), that is,

$$
\begin{aligned}
& i_{f d}=\frac{V_{e}^{*}}{r_{p f}}+\frac{r^{*}-r}{r_{f}} i_{d} \\
& V_{f d}=V_{e}-i_{f d} r_{f}
\end{aligned}
$$

Then, by substituting equations (11) (15) (19) (20) (21) into equation (18), this yield (26). Equation (26), which is respected to equation (18), can be considered as a set of 4 equations with 4 unknowns. Consequently, the final control law $d$ can be derived from the above equation. In this way, all the equations are related by the variables $K_{1}, K_{2}$, and $K_{3}$, i.e. the desired interconnection matrix $J_{d}$. The final control law contains information about all equations and state variables of the overall PCH models, i.e. $d$ is an expression of the state variables $x_{1}, x_{2}$, $x_{3}$, and $x_{4}$. Thus, the current and voltage on the $L C$ filter $\left(x_{1}\right.$ and $\left.x_{2}\right)$ are controlled as they are on the DC/DC converter ( $x_{3}$ and $x_{4}$ ). Furthermore, the variables $K_{1}, K_{2}$, and $K_{3}$ in $J_{d}$ vary with time and equilibrium point. Therefore, an adaptive interconnection matrix is attained in the proposed IDA-PBC. The control block diagram with the proposed IDA-PBC controller is given in Fig. 3.

\section{V.SIMULATION AND EXPERIMENTAL RESULTS}

To validate the proposed IDA-PBC control law, simulation results and experimental results are presented in this section. The parameters used are the same in both cases and are summarized in Table I. An experimental bench is implemented in the laboratory as shown in Fig. 4. It mainly consists of digital oscilloscope (TDS5034B), Switches (Semikron trench IGBTs SKM195GB126D), DC power supply (TDK-Lambda 600-17), as well as a dSPACE (ds1103).

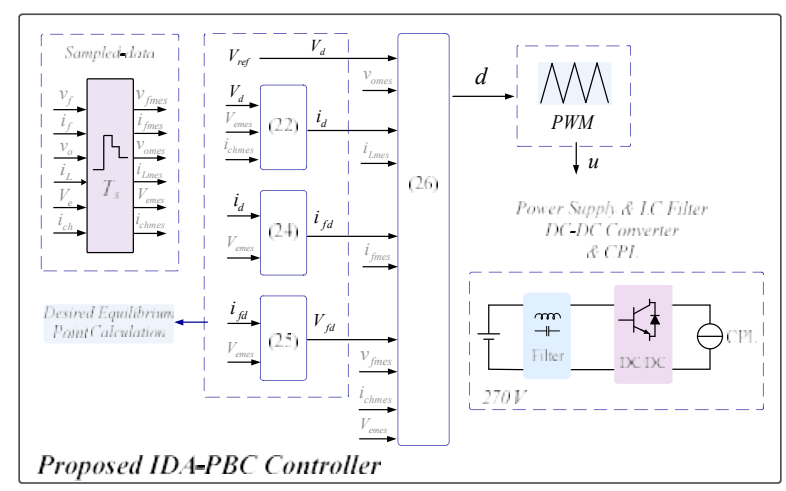

Fig. 3. Control block diagram of the studied system.

It is worth to be noted that the equivalent resistance $r$ and $r_{p}$ include some unmodeled losses in the system. It is why we considered them in the model, and why $r$ is greater than its nominal value. The parameters are chosen under the rated power of the CPL, i.e. $1 \mathrm{~kW}$. In the future research work, we will work on on-line parameter estimation to observe the losses parameters.

\section{A.Load Power Step and Damping Injection Results}

Due to the time-varying characteristic of the on-board DC microgrid, the power variation always occurs in practice. Therefore, it is necessary to test the proposed method in response to these kinds of changes. Fig. 5-12 represent the system behaviors when the load power step is applied. The state variables $x=\left[i_{f}, v_{f}, i_{L}, v_{o}\right]^{\mathrm{T}}$ and desired equilibrium point $x_{d}=\left[i_{f d}\right.$, $\left.V_{f d}, i_{d}, V_{d}\right]^{\mathrm{T}}$ are depicted in the same figure to demonstrate the effective tracking performance of the proposed control algorithm.

To begin with, the damping assignment technique is not implemented, the natural damping $\left(R=R_{d}\right)$ is used in IDA-PBC. Fig. 5 (simulation) and Fig. 6 (experimental results) illustrate the system performance after the CPL step from $1 \mathrm{~kW}$ to $3 \mathrm{~kW}$. The good performance of trajectory tracking in voltage and current are validated. However, a relatively large overshoot and long settling time are responded for this step. As shown, the system needs more than $0.04 \mathrm{~s}$ to reach its new equilibrium point.

$$
\begin{aligned}
& {\left[\begin{array}{cccc}
\frac{-r_{f}}{L_{f}{ }^{2}} & \frac{-1}{L_{f} C_{f}} & 0 & 0 \\
\frac{1}{L_{f} C_{f}} & \frac{-1}{r_{p f} C_{f}{ }^{2}} & \frac{-1}{L C_{f}} & 0 \\
0 & \frac{1}{L C_{f}} & \frac{-r}{L^{2}} & \frac{-1}{L C} \\
0 & 0 & \frac{1}{L C} & \frac{-1}{r_{p} C^{2}}
\end{array}\right]\left[\begin{array}{cccc}
L_{f} & 0 & 0 & 0 \\
0 & C_{f} & 0 & 0 \\
0 & 0 & L & 0 \\
0 & 0 & 0 & C
\end{array}\right]\left[\begin{array}{l}
x_{1} \\
x_{2} \\
x_{3} \\
x_{4}
\end{array}\right]+\left[\begin{array}{c}
0 \\
0 \\
\frac{x_{4}}{L} \\
\frac{-x_{3}}{C}
\end{array}\right] d+\left[\begin{array}{c}
\frac{V_{e}}{L_{f}} \\
0 \\
0 \\
\frac{-i_{c h}}{C}
\end{array}\right] } \\
&=\left[\begin{array}{cccc}
\frac{-r_{l}}{L_{f}{ }^{2}} & \frac{-1}{L_{f} C_{f}}-K_{3} & 0 & 0 \\
\frac{1}{L_{f} C_{f}}+K_{3} & \frac{-r_{2}}{C_{f}{ }^{2}} & \frac{-1}{L C_{f}}-K_{2} & 0 \\
0 & \frac{1}{L C_{f}}+K_{2} & \frac{-r_{3}}{L^{2}} & \frac{-1}{L C}-K_{I} \\
0 & 0 & \frac{1}{L C}+K_{l} & \frac{-r_{4}}{C^{2}}
\end{array}\right]\left[\begin{array}{cccc}
L_{f} & 0 & 0 & 0 \\
0 & C_{f} & 0 & 0 \\
0 & 0 & L & 0 \\
0 & 0 & 0 & C
\end{array}\right]\left[\begin{array}{l}
x_{1}-x_{I d} \\
x_{2}-x_{2 d} \\
x_{3}-x_{3 d} \\
x_{4}-x_{4 d}
\end{array}\right]+\left[\begin{array}{c}
\dot{x}_{l d} \\
\dot{x}_{2 d} \\
\dot{x}_{3 d} \\
\dot{x}_{4 d}
\end{array}\right]
\end{aligned}
$$


TABLE I

SYSTEM PARAMETERS

\begin{tabular}{lll}
\hline \hline Symbol & Quantity & Value \\
\hline$V_{e}$ & Input voltage & $270 \mathrm{~V}$ \\
$V_{\text {ref }}$ & Output voltage reference & $350 \mathrm{~V}$ \\
$L_{f}$ & Filter inductance & $246 \mu \mathrm{H}$ \\
$r_{f}$ & Filter inductor resistance & $0.05 \Omega$ \\
$C_{f}$ & Filter capacitance & $200 \mu \mathrm{F}$ \\
$r_{p f}$ & Filter capacitor insulation resistance & $10 \mathrm{M} \Omega$ \\
$L$ & Boost inductance & $950 \mu \mathrm{H}$ \\
$r$ & Boost inductor resistance & $0.2 \Omega$ \\
$C$ & Boost capacitance & $510 \mu \mathrm{F}$ \\
$r_{p}$ & Boost capacitor insulation resistance & $5 \mathrm{M} \Omega$ \\
$F_{s}$ & Frequency & $20 \mathrm{kHz}$ \\
\hline \hline
\end{tabular}

To solve this problem, the virtual damping is injected into the system $\left(R \neq R_{d}\right)$ to validate the damping assignment technique. This subsection shows the system performances for different values of $r_{3}$, which tightly related to the dynamic feature. Other damping factors are remaining in the natural value of the system. Regarding $r_{l}, r_{2}, r_{3}$, and $r_{4}$, as indicated in equation (17), all the eigenvalues of matrix $R_{d}$ affect the system stability. From this point, high values of $R_{d}$ are better for the system stability margins. In this section, $r_{1}, r_{2}$, and $r_{4}$ are chosen equal to their nominal values, related to the parameters defined in Table I (natural damping). This choice does not increase system stability margins.

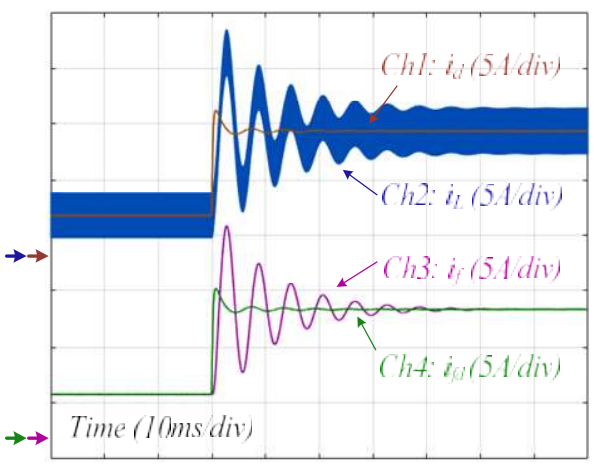

(a)

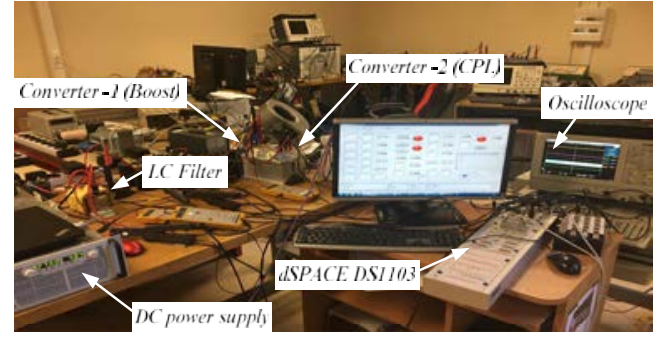

Fig. 4. Experimental bench.

However, the results show that the system does not have any instability issue, because the system is already stable with these nominal values (see Figs. 5-6). Of course, one can add more damping to the system using $r_{1}, r_{2}$, and $r_{4}$. But high damping factors will lead to duty cycles out of the range of $\left[\begin{array}{ll}0 & 1\end{array}\right]$ during the transient. In this case, the controller output $d$ saturates at 0 or 1 and the passivity proof is no longer satisfied. A good tradeoff is to find an effective parameter among $r_{1}, r_{2}, r_{3}$, and $r_{4}$ to inject the damping, and to keep the other parameters equal to the nominal values. We noticed that $r_{3}$ affects more effectively the dynamic of the system without saturating, so the passivity proof is satisfied. It is why we choose $r_{3}$ to inject the damping in this paper. In this way, the same simulation and experimental scenarios are performed and conducted. The simulation and experimental results of these cases are shown in Figs. 7-12.

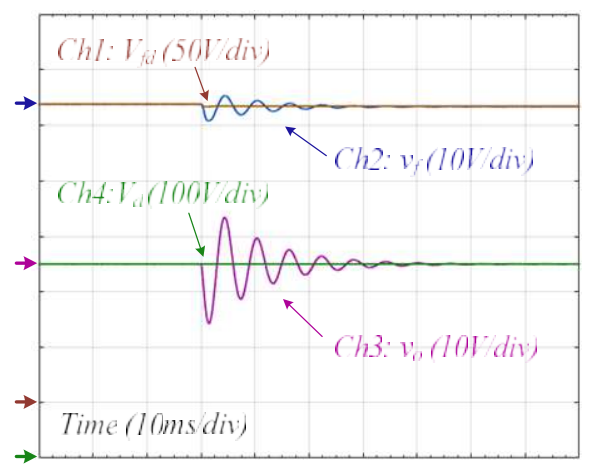

(b)

Fig. 5. System response when $r_{3}=0.2$ and CPL power steps from $1 \mathrm{~kW}$ to $3 \mathrm{~kW}$ (simulation).

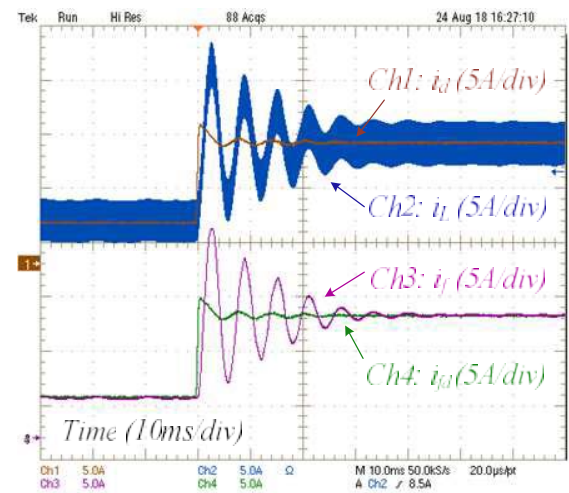

(a)

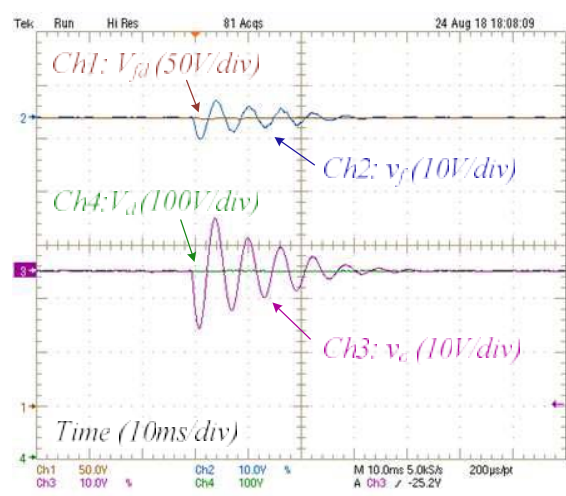

(b)

Fig. 6. System response when $r_{3}=0.2$ and CPL power steps from $1 \mathrm{~kW}$ to $3 \mathrm{~kW}$ (experimental results). 


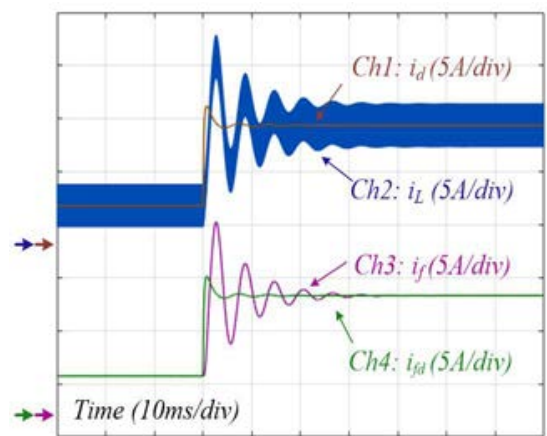

(a)

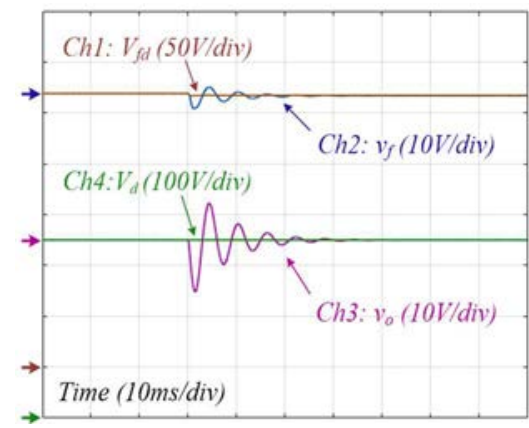

(b)

Fig. 7. System response when $r_{3}=0.3$ and CPL power steps from $1 \mathrm{~kW}$ to $3 \mathrm{~kW}$ (simulation).

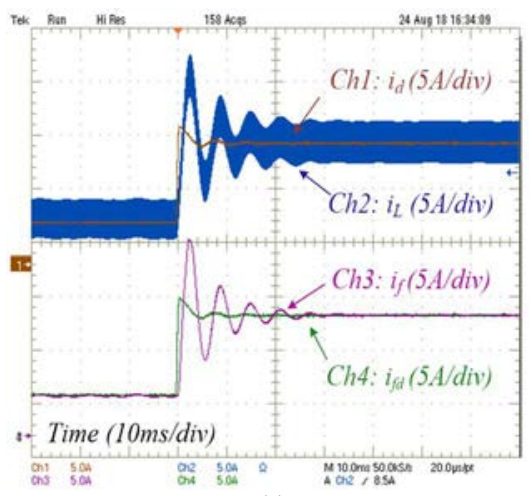

(a)

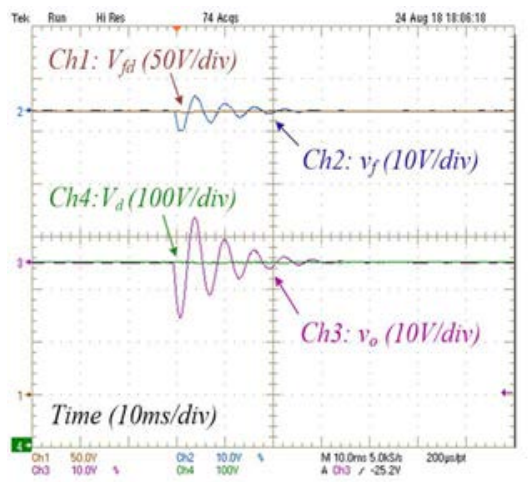

(b)

Fig. 10. System response when $r_{3}=0.3$ and CPL power steps from $1 \mathrm{~kW}$ to $3 \mathrm{~kW}$. (experimental results).

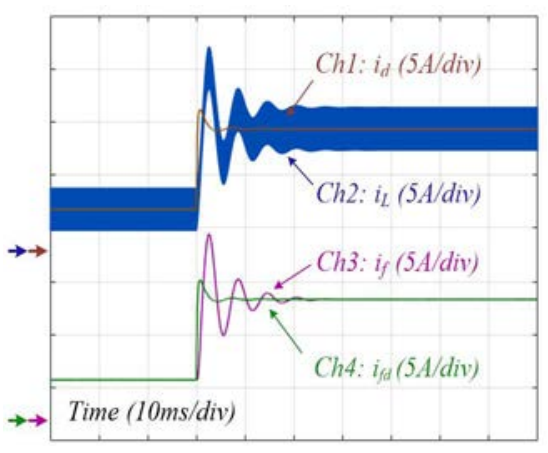

(a)

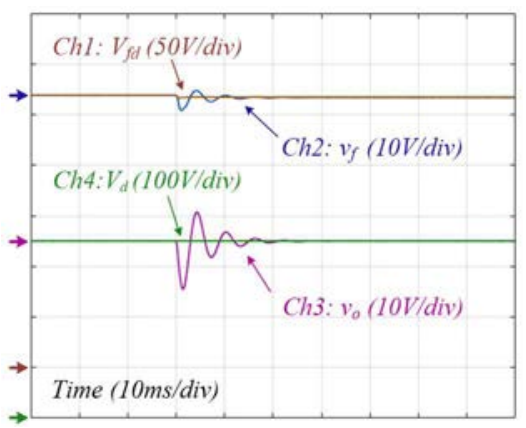

(b)

Fig. 8. System response when $r_{3}=0.4$ and CPL power steps from $1 \mathrm{~kW}$ to $3 \mathrm{~kW}$ (simulation).

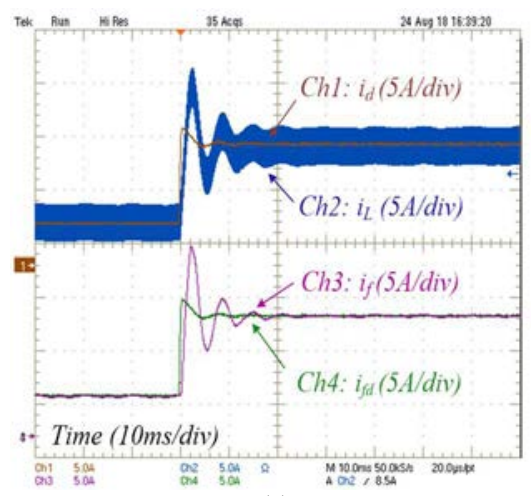

(a)

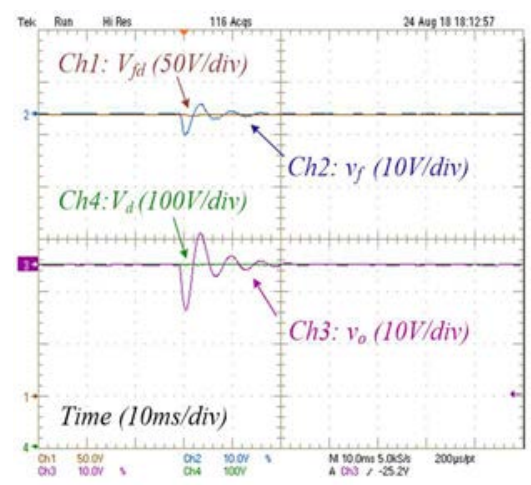

(b)

Fig. 11. System response when $r_{3}=0.4$ and CPL power steps from $1 \mathrm{~kW}$ to $3 \mathrm{~kW}$ (experimental results).

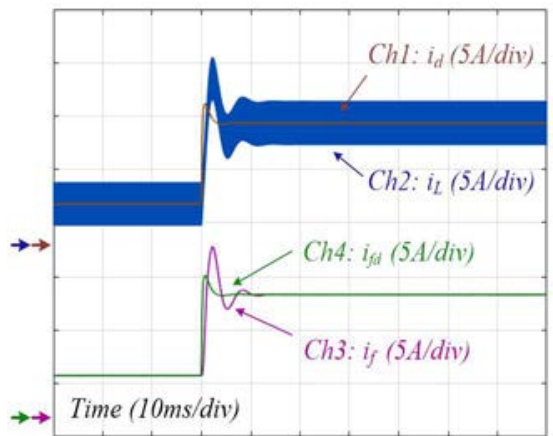

(a)

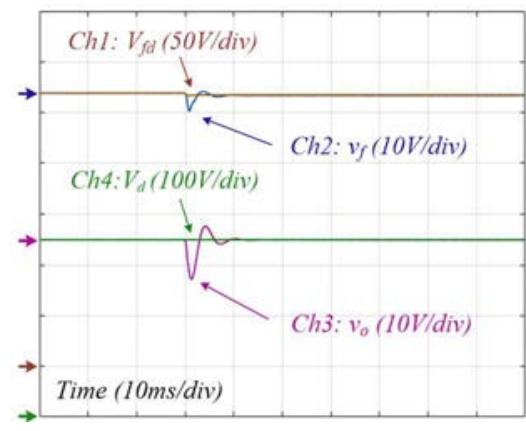

(b)

Fig. 9. System response when $r_{3}=0.8$ and CPL power steps from $1 \mathrm{~kW}$ to $3 \mathrm{~kW}$ (simulation).

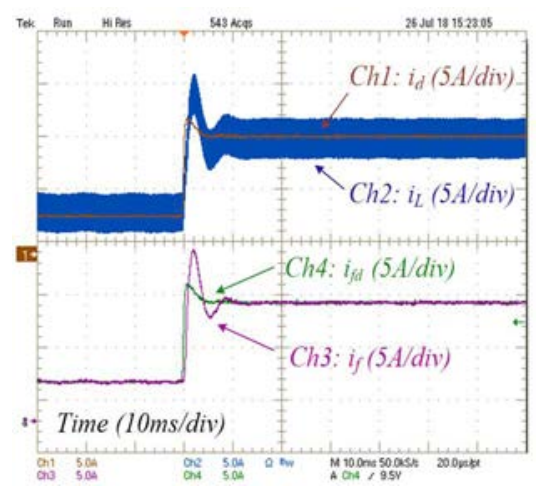

(a)

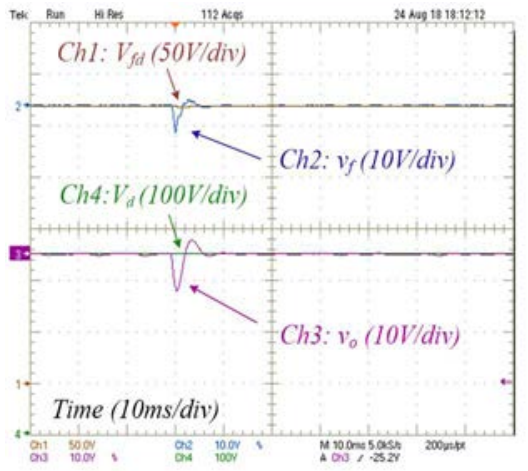

(b)

Fig. 12. System response when $r_{3}=0.8$ and CPL power steps from $1 \mathrm{~kW}$ to $3 \mathrm{~kW}$ (experimental results). 
Fig. 7 and Fig. 10 depict the dynamic waveforms of the cascaded system, when a slightly damping $\left(r_{3}=0.3\right)$ is injected into the system. As shown, the system takes about $0.03 \mathrm{~s}$ to reach the new equilibrium point. Compared with the no damping case, the overshoot and settling time of the system are correspondingly reduced.

Figs. 8-9 (and Figs. 11-12) show the dynamic performance, correspond, respectively, to the cases $r_{3}=0.4$ and $r_{3}=0.8$. It needs about $0.02 \mathrm{~s}$ and $0.01 \mathrm{~s}$ respectively to achieve the new equilibrium point. In the case of $r_{3}=0.8$, comparing the boost converter inductance current response in Fig. 5 and Fig. 6, the system witnesses the $0.01 \mathrm{~s}$ settling time compared to the 0.04 $\mathrm{s}$ settling time in Figs. 5-6. In addition, the peak current in no damping case (close to 21A) is larger than that in the case $r_{3}=0.8$ (close to $16 \mathrm{~A}$ ).

In summary, no matter how deep the damping is injected, all the elements in the system can rapid response and track to their desired value. The good performance of trajectory tracking in voltage and current are validated. In addition, the implementation of the damping assignment technique can significantly improve system performance. As the damping value increases, the overshoot and settling time decrease accordingly. Moreover, as expected, the experimental results and simulation results are identical.

\section{B. Output Voltage Reference Step}

In practical applications, the output voltage reference may also change according to the actual CPL requirement. However, it should be noted that for the transient process, the output voltage reference is obtained after filtering the step change by a low-pass filter to reduce the inrush current and the overshoot. Fig. 13 depicts the simulation waveform when $V_{\text {ref }}$ steps from $350 \mathrm{~V}$ to $400 \mathrm{~V}$ at different cut-off frequency of the proposed low-pass filter. Meanwhile, the CPL power is kept at $1 \mathrm{~kW}$ and $r_{3}$ is set to 0.8 .

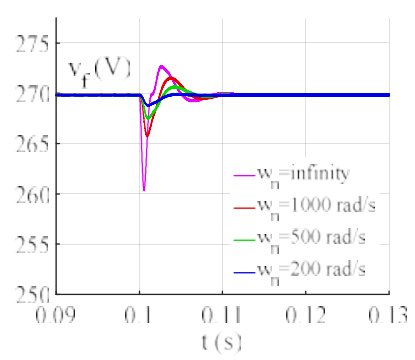

(a)

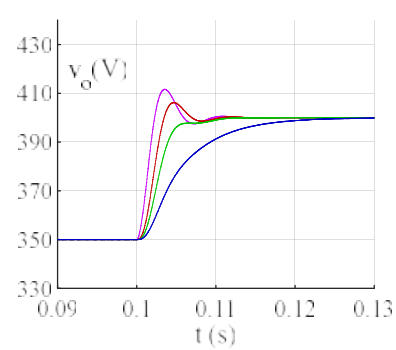

(c)

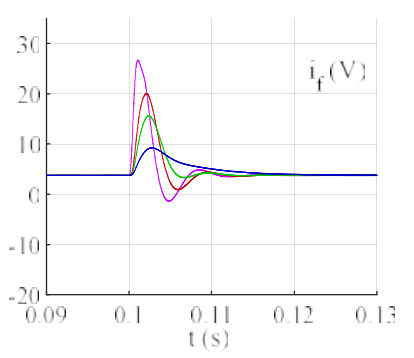

(b)

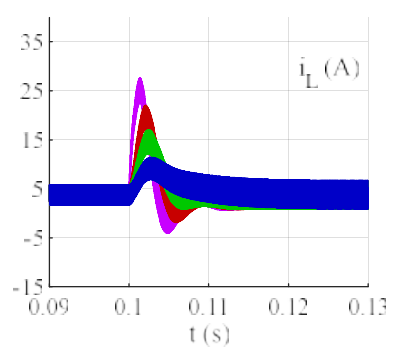

(d)
Fig. 13. Simulation results when output voltage reference step from $350 \mathrm{~V}$ to $400 \mathrm{~V}$.

As can be seen from Fig. 13, if a voltage reference step is used ( $w_{n}=$ infinity), there are large current peak and overshoot in the system response. The peak current of the inductor is about $28 \mathrm{~A}$ in both filter and converter. As the cut-off frequency decreases, this current is reduced accordingly. Likewise, when $w_{n}=200 \mathrm{rad} / \mathrm{s}$, the peak current has been reduced to $9 \mathrm{~A}$. Simultaneously, the decrease of the peak current and overshoot comes at the expense of increasing settling time. As shown, the output voltage needs about $0.025 \mathrm{~s}$ to reach $400 \mathrm{~V}$ in the case of $w_{n}=200 \mathrm{rad} / \mathrm{s}$. Compared with the case without the filter, it takes a relatively long time to step the voltage up.

Furthermore, to compare the simulation results with experimental results, the same step change and control parameters are implemented. Considering the current limitation, only part of the content is tested and verified. Figs. 14 shows the behavior of the system for different cut-off frequency $\left(w_{n}=200 \mathrm{rad} / \mathrm{s}\right.$ and $\left.500 \mathrm{rad} / \mathrm{s}\right)$ of the filter when the output voltage reference is stepped from $350 \mathrm{~V}$ to $400 \mathrm{~V}$. Consequently, the simulation results and the experimental validations are in good agreement.

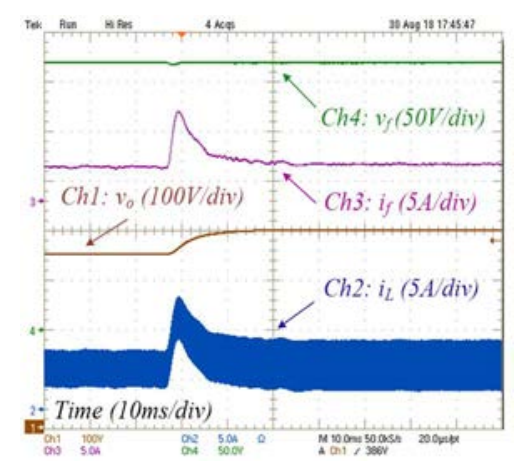

(a)

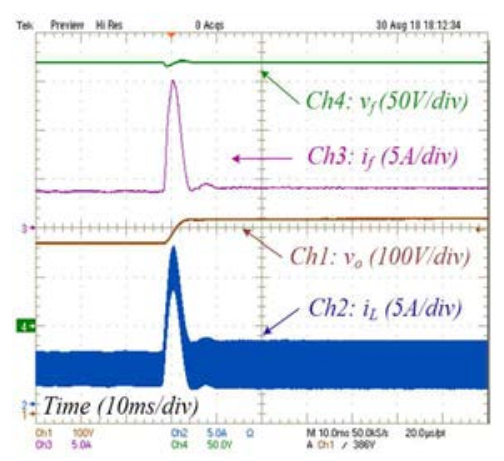

(b)

Fig. 14. Experimental results when output voltage reference steps from $350 \mathrm{~V}$ to $400 \mathrm{~V}$. (a) $w_{n}=200 \mathrm{rad} / \mathrm{s} \mathrm{(b)} w_{n}=500 \mathrm{rad} / \mathrm{s}$

\section{Input Voltage Variation}

In order to demonstrate more details on the controller performance, some experimental results with transients on the input voltage are performed. The CPL power is also kept at 1 $\mathrm{kW}$ and $r_{3}$ is set to 0.8 . Initially, Fig. 15 illustrates the simulation results when the input voltage steps up from $270 \mathrm{~V}$ to $300 \mathrm{~V}$. As in practice, a sudden change never happens on the DC-bus voltage, this step change signal is filtered by a low-pass filter. Fig. 15 shows that, without this filter ( $w_{n}=$ infinity), there is a large overshoot in the $L C$ filter and the current $i_{f}$ and $i_{L}$ become negative. 


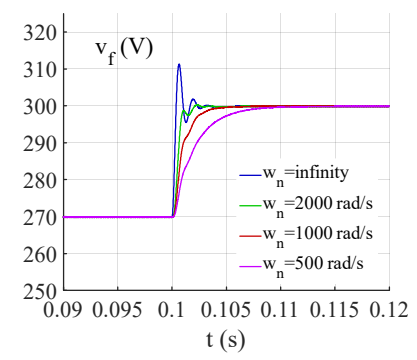

(a)

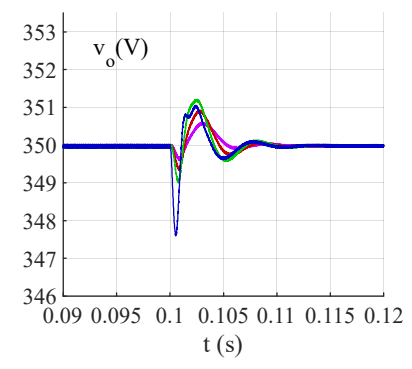

(c)

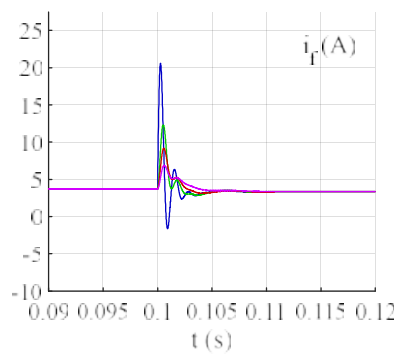

(b)

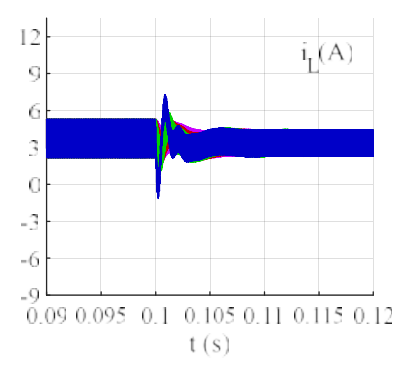

(d)
Fig. 15. Simulation results when input voltage steps from $270 \mathrm{~V}$ to $300 \mathrm{~V}$.

In order to test experimentally the performance of the proposed controller, the step input voltage disturbance from 270 $\mathrm{V}$ to $300 \mathrm{~V}$ is applied to the system via DC power supply (controlled by dSPACE). It is tested that, the real step signal in dSPACE lead to a $2 \mathrm{~ms}$ settling time step change ( $270 \mathrm{~V}$ to 300 $\mathrm{V})$ with $10 \mathrm{~V}$ overshoot in practice. The experimental results are presented in Fig. 16. It can be observed during the transient, with the proposed controller, that the system shows a good robustness against input voltage disturbance.

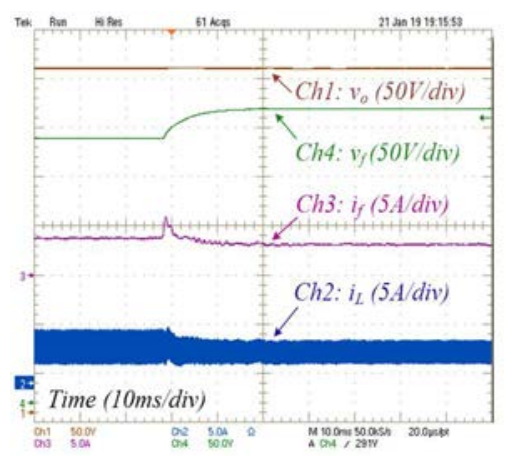

(a)

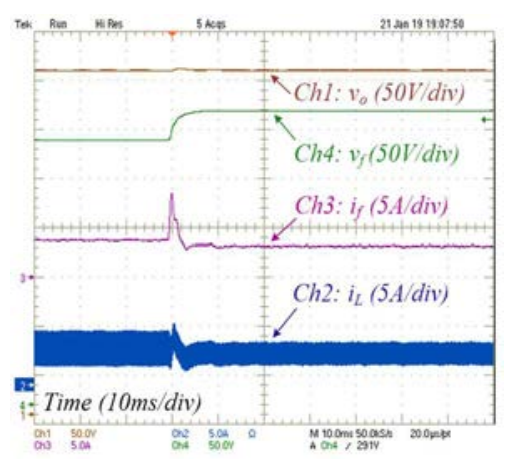

(b)

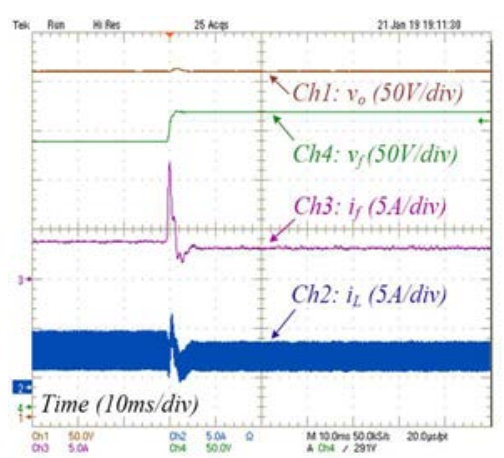

(c)

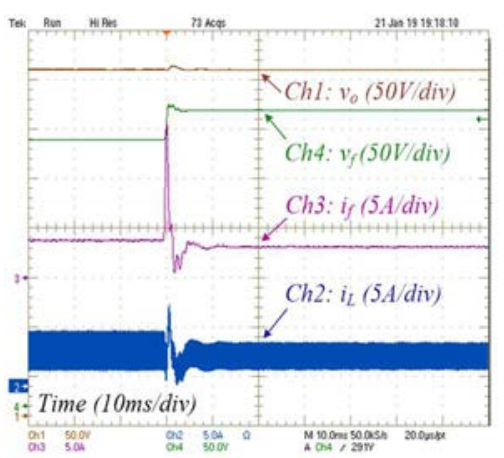

(d)

Fig. 16. Experimental results when input voltage steps from $270 \mathrm{~V}$ to $300 \mathrm{~V}$. (a) $w_{n}=200 \mathrm{rad} / \mathrm{s}(\mathrm{b}) w_{n}=500 \mathrm{rad} / \mathrm{s}$ (c) $w_{n}=1000 \mathrm{rad} / \mathrm{s}(\mathrm{d}) w_{n}=2000 \mathrm{rad} / \mathrm{s}$

Finally, to verify the effect of an input voltage sinusoidal disturbance on the system, the input voltage is changed to $V_{e}=270+5 \sin (100 \pi t)$. The corresponding responses are shown in Fig. 17. As can be seen, the controller can reject the sinusoidal disturbance on the output voltage.

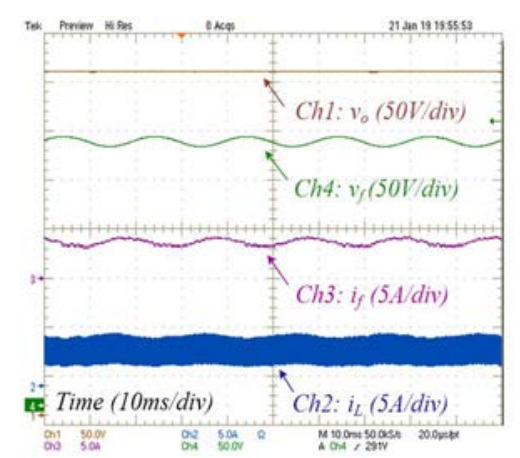

Fig. 17. Experimental results with sinusoidal input voltage disturbance.

According to the three groups of verifications mentioned above, it proves that the proposed control strategy is robust, effective and feasible in practice.

\section{VI.CONCLUSION}

This paper introduces a modified IDA-PBC for an $L C$ input filter cascaded with a DC/DC boost converter supplying a CPL. The plant is described using PCH form. The presented model considers all the energy storage units in the system including 
the $L C$ filter and the DC/DC converter dynamics. Then, an adaptive interconnection matrix is proposed to realize internal links in PCH models and generate a unique control law. This latter takes into account the dynamic behavior due to interactions between the filter and the converter, which are mostly neglected in the literature. Furthermore, a modified IDA-PBC and the proof of stability are presented here while the loads are variable. The damping assignment technique confirms to improve the transient performance of the IDA-PBC. Therefore, the passivity property of the whole system $L C$ input filter-DC/DC converter is ensured. This allows simplifying the stability analysis of an on-board DC microgrid containing this type of subsystems. The simulation and experimental results are given to demonstrate the effectiveness of the proposed method.

\section{REFERENCES}

[1] S. Yousefizadeh, J. D. Bendtsen, N. Vafamand, M. H. Khooban, F. Blaabjerg, and T. Dragičević, "Tracking control for a dc microgrid feeding uncertain loads in more electric aircraft: Adaptive backstepping approach," IEEE Trans. Ind. Electron., vol. 66, no. 7, pp. 5644-5652, July 2019.

[2] F. Gao, S. Bozhko, G. Asher, and P. Wheeler, "An improved voltage compensation approach in a droop-controlled dc power system for the more electric aircraft," IEEE Trans. Power. Electron., vol. 31, no. 10, pp. 7369-7383, Oct. 2016.

[3] $\mathrm{H}$. Xu, et al, "Analysis, comparison and discussion of control strategies for dual stator-winding induction generator dc generating system," IEEE J. Emerg. Sel. Topics Power Electron., vol. 4, no. 3, pp. 1007-1014, Sept. 2016.

[4] L. Herrera, W. Zhang, and J. Wang. "Stability analysis and controller design of DC microgrids with constant power loads," IEEE Tran. Smart Grid, vol. 8, no. 2, pp. 881-888, Mar. 2017.

[5] S. Pang, et al, "IDA-passivity-based control for boost converter with lc filter supplying constant power load," in Proc. IEEE Int. Conf. Elect. Syst. Aircraft, Railway, Ship Propuls. Road Vehicles, pp.1-6, Nov. 2018.

[6] K. W. Wang, X. Zhang, and H. S. H. Chung, "Solid-state single-port series damping device for power converters in dc microgrid systems," IEEE Trans. Power. Electron., vol. 34, no. 1, pp. 192-203, Jan. 2019.

[7] Y. Huangfu, et al. "Stability analysis and active stabilization of on-board DC power converter system with input filter," IEEE Trans. Ind. Electron., vol. 65 , no. 1, pp. 790-799, Jan. 2018.

[8] H. Bai, X. Wang, F. Blaabjerg, and P. C. Loh, "Harmonic analysis and mitigation of low-frequency switching voltage source inverter with auxiliary VSI," IEEE J. Emerg. Sel. Topics Power Electron., vol. 6, no. 3, pp. 1355-1365, Sept. 2018.

[9] S. Pang, et al, "Fault-tolerant consideration and active stabilization for floating interleaved boost converter system," in Proc. IEEE Ind. Electron. Soc. Annu. Meeting, pp. 7947-7952, Oct.-Nov. 2017.

[10] Y. Huangfu, et al. "Analysis and design of an active stabilizer for a boost power converter system," Energies, vol. 9, no. 11, pp. 934, Nov. 2016.

[11] M. A. Hassan, et al, "Adaptive passivity-based control of DC/DC buck power converter with constant power load in de microgrid systems," IEEE J. Emerg. Sel. Topics Power Electron., 2018.

[12] K. Areerak, et al, "Adaptive stabilization of uncontrolled rectifier-based ac-dc power systems feeding constant power loads," IEEE Trans. Power. Electron., vol. 33, no. 10, pp. 8927-8935, Oct. 2018.

[13] S. Pang, et al, "Interconnection and damping assignment passivity-based control applied to on-board dc-dc power converter system supplying constant power load," IEEE Trans. Ind. Appl., 2019. DOI: 10.1109/TIA.2019.2938149

[14] S. Pang, et al, "IDA-passivity-based control for on-board dc power converter system with constant power load," in Proc. IEEE Ind. Appl. Soc. Annu. Meeting, pp.1-6, Sept. 2018.

[15] N. Vafamand, M. H. Khooban, T. Dragičević, and F. Blaabjerg, "Networked fuzzy predictive control of power buffers for dynamic stabilization of DC microgrids," IEEE Trans. Ind. Electron., vol. 66, no. 2, pp. 1356-1362, Feb. 2019.

[16] S. Yousefizadeh, J. D. Bendtsen, N. Vafamand, M. H. Khooban, F.
Blaabjerg, and T. Dragičević, "EKF-based predictive stabilization of shipboard DC microgrids with uncertain time-varying load," IEEE $J$. Emerg. Sel. Topics Power Electron., vol. 7, no. 2, pp. 901-909, June 2019.

[17] M. Zhang, Y. Li, F. Liu, L. Luo, Y. Cao, and M. Shahidehpour, "Voltage stability analysis and sliding-mode control method for rectifier in dc systems with constant power loads," IEEE J. Emerging Sel. Topics Power Electron., vol. 5, no. 4, pp. 1621-1630, Dec. 2017.

[18] N. Vafamand, M. H. Khooban, T. Dragičević, F. Blaabjerg, and J. Boudjadar, "Robust non-fragile fuzzy control of uncertain DC microgrids feeding constant power loads," IEEE Trans. Power. Electron., 2019. DOI: 10.1109/TPEL.2019.2896019.

[19] N. Vafamand, A. Khayatian, and M. H. Khooban, "Stabilization and transient performance improvement of DC MGs with CPLs: non-linear reset control approach," IET Generation, Transmission \& Distribution, vol. 13, no. 14, pp. 3169-3176, July. 2019.

[20] A. Mitiche, A. B. Houda, and L. Mitiche. "Multivariable systems model reduction based on the dominant modes and genetic algorithm," IEEE Trans. Ind. Electron., vol. 64, no. 2, pp. 1617-1619, Feb. 2017.

[21] Y. C. Chang, C. H. Chen, Z. C. Zhu, and Y. W. Huang, "Speed control of the surface-mounted permanent-magnet synchronous motor based on Takagi-Sugeno fuzzy models," IEEE Trans. Power. Electron., vol. 31, no. 9, pp. 6504-6510, Sept. 2016.

[22] W. Du, J. Zhang, Y. Zhang, and Z .Qian, "Stability criterion for cascaded system with constant power load," IEEE Trans. Power. Electron., vol. 28, no. 4, pp. 1843-1851, April 2013.

[23] B. P. Loop, S. D. Sudhoff, S. H. Zak, and E. L. Zivi, "Estimating regions of asymptotic stability of power electronics systems using genetic algorithms," IEEE Trans. Control Syst. Technol., vol. 18, no. 5, pp. 10111022, Sept. 2010.

[24] S. Pang, et al. "Improving the stability of cascaded dc-dc converter systems via the viewpoints of passivity-based control and port-controlled Hamiltonian framework," in Proc. IEEE Ind. Appl. Soc. Annu. Meeting, pp. 1-6, Sept.-Oct. 2019.

[25] H. K. Khalil, Nonlinear systems. New Jersey: Prentice-Hall, 2002.

[26] Y. Gu, W. Li, X. He. "Passivity-based control of de microgrid for selfdisciplined stabilization," IEEE Trans. Power Syst, vol. 30, no. 5, pp. 2623-2632, Sept. 2015

[27] R. Xu, et al, "A novel control method for transformer less H-bridge cascaded STATCOM with star configuration," IEEE Trans. Power. Electron., vol. 30, no. 3, pp. 1189-1202, Mar. 2015.

[28] R. Cisneros, F. Mancilla-David, and R. Ortega. "Passivity-based control of a grid-connected small-scale windmill with limited control authority," IEEE J. Emerg. Sel. Topics Power Electron., vol. 1, no. 4, pp. 247-259, Dec. 2013.

[29] V. Petrovic, and R. Ortega, "Interconnection and damping assignment approach to control of PM synchronous motors," IEEE Trans. Control Syst. Technol., vol. 9, no. 6, pp. 811-820, Nov. 2001.

[30] R. Ortega, A. Schaft, and B. Maschke, "Interconnection and damping assignment passivity-based control of port-controlled Hamiltonian systems," Automatica, vol. 38, no. 4, pp. 585-596, Apr. 2002.

[31] J. Zeng, Z. Zhang, and W. Qiao. "An interconnection and damping assignment passivity-based controller for a DC/DC boost converter with a constant power load," IEEE Trans. Ind. Appl., vol. 50, no. 4, pp. 23142322, July-Aug. 2014.

[32] Y. Gui, B. Wei, M. Li, J. M. Guerrero, and J. C. Vasquez, "Passivitybased coordinated control for islanded AC microgrid," Applied Energy, vol. 229, pp. 551-561, Nov. 2018.

[33] Y. Meng, S. Shang, H. Zhang, Y. Cui and X. Wang. "IDA-PB control with integral action of Y-connected modular multilevel converter for fractional frequency transmission application," IET Gener. Transm. Distrib., vol. 12, no. 14 , pp. 3385-3397, Aug. 2017.

[34] R. V. Meshram, "Port-controlled phasor Hamiltonian modeling and IDAPBC control of solid-state transformer," IEEE Trans. Control Syst. Technol., vol. 27, no. 1, pp.161-174, Jan. 2019.

[35] Q. Zhang and G. Liu. "Precise control of elastic joint robot using an interconnection and damping assignment passivity-based approach," IEEE Trans. Mechatron., vol. 21, no. 6, pp. 2728-2736, Dec. 2016.

[36] R. Ortega, and E. Garcia-Canseco. "Interconnection and damping assignment passivity-based control: A survey," Eur. J. control, vol. 10, no. 5, pp. 432-450, Dec. 2004. 